\title{
USO DE CLORANFENICOL NA GESTAÇÃO
}

\author{
Chloramphenicol use in pregnancy
}

\author{
Fernando de S. Del Fiol ${ }^{*^{1}}$, Andrea de M. Avallone ${ }^{2}$ \\ ${ }^{1}$ Professor do Curso de Farmácia da Universidade de Sorocaba - SP. \\ ${ }^{2}$ Aluna do Curso de Farmácia da Universidade de Sorocaba - SP.
}

Autor para correspondência: e-mail: fernando.fiol@uniso.br.

Recebido em 23/05/2005 - Aceito em 16/06/2005

\begin{abstract}
RESUMO: A gestação representa um problema terapêutico único, quando ao se prescrever um medicamento nesta situação especial, na verdade se está atingindo dois organismos simultaneamente. $\mathrm{O}$ adequado tratamento de pacientes gestantes deve considerar, além do(s) agente(s) etiológico(s), o local da infecção, a farmacocinética do antimicrobiano e principalmente a possibilidade de efeitos deletérios para o binômio gestante-feto. A prática clínica tem demonstrado que o uso de antibióticos beta-lactâmicos não tem trazido riscos à formação do feto e ao desenvolvimento infantil. Os níveis de resistência dos microrganismos aos antimicrobianos têm aumentando de forma alarmante em todo o mundo de forma que muitas vezes o prescritor terá que fazer outras opções além dos já consagrados beta-lactâmicos. Em outras situações, pode não haver alternativa terapêutica, como no caso de infecções causadas por S. typhi ou meningites por $H$. influenzae e $N$. meningitidis. Nestes casos há a necessidade da prescrição do cloranfenicol embora a literatura relate casos de síndrome cinzenta e danos hematológicos para o recém-nascido. Este trabalho mostra uma ampla revisão bibliográfica acerca do uso deste fármaco na gestação e suas implicações.
\end{abstract}

PALAVRAS-CHAVE: gestação, cloranfenicol, teratogênese.

ABSTRACT: Pregnancy represents an unique therapeutic problem. When prescribing over this special condition, the physician must remember that the prescription will affect two people and the drug must treat the mother without affect the fetus. The correct treatment of these women, however, must consider along with pathogens, the infection site and antibiotic pharmacokinetics, the fetus and possible side effects to the child. Betalactams antibiotics having a long history of use without significant deleterious effects on the fetuses still are the safest choice during pregnancy. However, considering the constant increase of multi-resistant microorganisms, the physician has been forced to use some kind of different antimicrobial agent. In some situations we cannot have therapeutic options. S. typhi infections or $H$. influenzae and $N$. meningitidis meningitis must be treated with chloramphenicol, although many reports of gray baby syndrome and hematological effects in newborns. The present study is a wide revision regarding the use of this drug during pregnancy.

KEYWORDS: pregnancy, chloramphenicol, teratogenisis.

\section{INTRODUÇÃO}

Fármacos na gestação: A utilização de medicamentos por gestantes tem sido uma prática evitada desde o acidente da talidomida ocorrida entre 1950 e 1960 (MENGUE et al., 2004). A partir desse fenômeno, foram exigidos estudos que garantissem a segurança dos medicamentos para uso durante a gestação (PETERS, 1993). Alguns estudos conduzidos no Brasil mostram que entre 83,8\% (MENGUE et al., 2001) e 97,6\% (GOMES et al., 1999) das gestantes no país são expostas a, pelo menos, um medicamento durante a gestação, com uma média de 4,2 medicamentos por gestação (MENGUE et al., 2001). Nestes estudos, a exposição a antibióticos no período 
gestacional esteve em torno de 11 a 15\% das gestantes, sendo que a grande maioria foi motivada por infecções urinárias ou respiratórias.

Os exemplos de infecções mais comuns durante a gestação, são as infecções do trato urinário, as quais devem ser tratadas adequadamente para que não comprometam a saúde materna e fetal. Tais infecções, se não forem tratadas, podem ser transferidas ao feto, induzir nascimentos prematuros e de crianças com baixo peso (RAO \& ARULAPPU, 1981). Alguns autores relatam que infecções urinárias não tratadas em gestantes estão associadas a um aumento de até $50 \%$ no risco de nascidos de baixo peso e de parto prematuro, eclampsia, hipertensão, anemias além de endometriose pós-parto (CHRISTENSEN, 2000).

As infecções urinárias, tais como bacteremias, cistites e pielonefrites estão entre as mais comuns, estimando-se que 2 a 7\% de todas as mulheres desenvolvem algum tipo de infecção urinária na gestação as quais deverão ser tratadas com o auxílio de fármacos de ação antibacteriana (DASHE \& GILSTRAP, 1997).

O risco fetal pelo uso de fármacos sempre vai existir, pois os antibióticos, em geral, apresentam baixo peso molecular facilitando a difusão através da placenta e excreção pelo leite, expondo o feto e o neonato aos possíveis efeitos tóxicos desses fármacos (DASHE \& GILSTRAP, 1997). Há necessidade, desta forma, de estabelecer uma relação risco-benefício ao empregar um antibiótico em uma gestante, ou seja, deve-se questionar se o benefício da utilização de um antibiótico na gestante é maior do que o risco de possíveis alterações no feto.

Se a resposta for afirmativa e a terapêutica estabelecida, há a necessidade de o clínico conhecer muito bem, os possíveis riscos a que o feto estará exposto em função do antibiótico que será escolhido para iniciar a terapia.

Os dados relativos à segurança e eficácia do uso de antibióticos durante a gestação são muito escassos em virtude da dificuldade em estudar a ação desses fármacos em fetos e neonatos. Os estudos clínicos e epidemiológicos relacionados à segurança de antibióticos, por questões éticas e legais são realizados em mulheres não grávidas e seus resultados extrapolados para gestantes. Além disso, diversas alterações fisiológicas que ocorrem na gestante interferem diretamente na farmacocinética dos antibióticos, podendo levar a aumentos na concentração plasmática e efeitos tóxicos desses fármacos ou ainda a concentrações plasmáticas subinibitórias, anulando o feito do antibiótico, trazendo como conseqüência o insucesso terapêutico e o aparecimento de resistência bacteriana (SA DEL FIOL et al., 2000).

Categoria de fármacos empregados na gestação: Devido ao potencial risco de uso de medicamentos durante a gestação, a FDA (Food and Ddrug Administration), criou cinco categorias de fármacos a serem usadas por gestantes, a qual deve estar incluída em todas as bulas de medicamentos.

Classificação de fármacos segundo a FDA:

Categoria A: fármacos que, em estudos controlados em mulheres, não demonstraram risco para o feto no primeiro trimestre, nem nos outros trimestres, sendo remota a possibilidade de causar dano fetal.

Categoria B: fármacos que, em estudos de reprodução animal, não demonstram risco fetal, mas não possuem estudos controlados em mulheres gestantes; ou então, os estudos de reprodução animal mostram efeitos adversos (diferentes de fertilidade diminuída) que não foram confirmados em estudos controlados de mulheres, no primeiro trimestre de gestação, não havendo risco nos outros trimestres.

Categoria C: fármacos que, em estudos de reprodução animal, demonstraram efeitos adversos no feto (teratogênicos, embriocidas ou efeitos adversos) e não há estudos controlados em mulheres; ou então, não existem estudos em mulheres nem em animais. Os fármacos desta categoria só devem ser administrados se o benefício potencial justificar o risco para o feto.

Categoria D: fármacos em que há evidencia positiva de risco fetal humano, mas os benefícios para a mulher grávida podem ser aceitáveis apesar do risco, como, por exemplo, em doenças graves ou que ameaçam a vida, e para as quais não existam outros fármacos mais seguros; na literatura e bula destes fármacos, deve ser registrado um aviso do seu risco potencial.

Categoria $X$ : fármacos que em estudos animais e em pacientes humanos demonstraram anormalidades fetais, e o risco do seu uso, em mulheres gestantes não justifica qualquer beneficio possível. Os fármacos desta categoria são contra-indicadas em mulheres gestantes ou que ficarão grávidas. Nas bulas e literatura destes fármacos, o fato deve ser registrado no item de contra-indicações (ADDIS, et al., 2000).

Antibióticos na gestação: Durante a gestação, como em qualquer outra fase da vida, o organismo humano está sujeito a adquirir infecções. Se não tratadas correta e adequadamente, essas infecções poderão levar à morte da mãe, do feto ou de ambos. Dessa forma, não há alternativa para o clínico a não ser fazer o uso de antibióticos 
durante esse período da vida. Para que o prescritor possa empregar uma terapia eficaz e ao mesmo tempo segura, alguns fatores devem ser considerados, além da sensibilidade do microrganismo e da localização topográfica do foco infeccioso:

1. Histórico da segurança do fármaco: os agentes beta-lactâmicos têm sido empregados durante a gestação desde sua introdução na prática clínica, na década de 40 sem qualquer relato de teratogenicidade. A explicação para esse fato reside no mecanismo de ação do antibiótico que atua interferindo na síntese da parede celular bacteriana, estrutura não encontrada na célula humana de modo que não há receptor para atuação do fármaco na célula humana.

2. Farmacocinética do antibiótico: alguns antibióticos alteram de maneira significativa sua farmacocinética durante a gestação. As alterações fisiológicas ocorridas na gestante podem modificar completamente o comportamento de fármacos. Aumento do volume sanguíneo, aumento da filtração glomerular, e atividade hepática podem diminuir muito a concentração plasmática de alguns antibióticos (PRESTON, 2004). As cefalosporinas têm uma diminuição em torno de $30 \%$ na concentração plasmática de gestantes quando comparadas a mulheres não gestantes (PHILIPSON et al., 1987).

3. Período gestacional: a segurança de muitos fármacos é dependente do período gestacional em que foram empregados.

O primeiro trimestre começa com a concepção e continua até a décima primeira semana, entre os dias 0 e 70 após a concepção (MOORE, 1982). Essa fase da gestação é marcada por alterações hormonais importantes, resultando em aumento do volume sanguíneo, de taxas de filtração renal e metabolização hepática (NIEBYL, 1984). O risco de teratogenia (anencefalia e focomegalia) e perda fetal é muito alto nesta fase, especialmente até o décimo oitavo dia após a fecundação, dia coincidente com a falta da próxima menstruação, momento em que a mulher começa a perceber seu estado gestacional. Embora a grande maioria das mulheres não conheça seu estado de gestante nesta fase, é muito importante evitar qualquer fármaco neste período. Antibióticos a serem evitados durante este período: rifampicina, metronidazol e tetracilclinas.

O segundo trimestre dá-se entre o dia 71 e 154 dias após a concepção. Nesta fase da gestação, todas as estruturas internas e externas já estão desenvolvidas (NIEBYL, 1984) e passarão por fases de crescimento e posterior diferenciação. Nesta fase não é recomendada a utilização de fármacos com qualquer atividade antimetabólica, especialmente quando há o envolvimento de ácidos nucléicos. Na classe dos antibióticos, maior preocupação deve ser dispensada às sulfas e antagonistas do folato (WHIPKEY et al., 1984). Antibióticos a serem evitados neste período: aminoglicosídeos e tetraciclinas

O terceiro trimestre ocorre entre o dia 155 até o momento do parto. Durante essa fase há uma dificuldade muito grande de metabolização de fármacos, pois até o momento do parto, qualquer que seja o agente, a metabolização e excreção ocorrerão por conta da mãe e logo após o parto, o recém-nascido dependerá de seu próprio processo de metabolização ainda imaturo (BEELEY, 1986). Antibióticos a serem evitados durante esta fase da gestação: sulfonamidas, quinolonas e cloranfenicol.

Placenta: a gestação caracteriza-se pela formação de um órgão ímpar, a placenta, que tem duração limitada. Esse órgão desempenha funções diversificadas, tais como: intestino fetal; responsável pelo suprimento de nutrientes; pulmão fetal, nas trocas de oxigênio e dióxido de carbono; rim fetal, na regulação dos volumes líquidos e na eliminação dos metabólicos de refugo; glândula endócrina versátil, que sintetiza muitos hormônios esteróides e protéicos que irão afetar o metabolismo, tanto materno quanto fetal (BERNE \& LEVY, 2000). A principal função da placenta é a de possibilitar a difusão de nutrientes do sangue da mãe para o do feto e a difusão dos produtos de excreção do feto para a mãe. Porém, nos primeiros meses da gestação, a membrana placentária é espessa porque não está plenamente desenvolvida, tendo uma permeabilidade baixa, e ainda sua área de superfície é pequena, havendo baixa difusão. Entretanto, à medida que a placenta envelhece, sua permeabilidade vai aumentando progressivamente até quase o último mês da gestação (MYLLYNEN et al., 2005).

Cloranfenicol na gestação: o cloranfenicol é um antibiótico produzido pelo Streptomyces venezuelae, um microorganismo isolado pela primeira vez em 1947, em uma amostra de solo coletada na Venezuela, por Burkholder e por pesquisadores da universidade de Illinois e foi caracterizada e denominada cloromicetina. Neste mesmo ano foi empregado em um surto de tifo epidêmico na Bolívia e num surto de tifo exantemático na Península Malaia, ambos com resultados extraordinários (REYES, 1987)

O cloranfenicol é um potente inibidor da síntese de proteínas microbianas e em menor grau, em células eucarióticas (RUIZ \& RAMIREZ, 1990). A substância penetra rapidamente nas células bacterianas, provavelmente por um mecanismo de difusão facilitada. Liga-se reversivelmente a um sítio receptor existente na subunidade $50 S$ do ribossomo bacteriano. O fármaco parece impedir a ligação da extremidade contendo aminoácido do aminoacil 
tRNA ao local aceptor na subunidade ribossômica 50S (GREENWOOD, 1997). O fármaco também pode inibir a síntese de proteínas mitocôndriais nas células de mamíferos, talvez pelo fato de os ribossomos mitocôndrias assemelharem-se aos ribossomos bacterianos (ambos são 70S) do que os ribossomos citoplasmáticos de $80 \mathrm{~S}$ das células de mamíferos. A peptidiltransferase dos ribossomos mitocondriais, mas não dos ribossomos citoplasmáticos, é sensível a ação inibitória do cloranfenicol.

O cloranfenicol é um antimicrobiano de espectro relativamente amplo, predominantemente bacteriostático, atuando contra gram positivos, gram negativos, riquétsias, clamídias e micoplasmas. As salmonelas são geralmente sensíveis e os principais agentes causadores da meningite na infância (H. influenzae e $N$. meningitidis) apresentam grande sensibilidade, o que fez com que seu uso aumentasse muito nos últimos anos no tratamento da meningite do neonato (BUTHA et al., 1980).

O cloranfenicol está disponível em duas formas para administração oral: o próprio fármaco na forma ativa e o pró-fármaco inativo - o palmitato. Por apresentar baixo peso molecular, é absorvido de maneira rápida e completa pelo trato gastrintestinal (REYES et al., 1987). Distribui-se adequadamente nos líquidos corporais e atinge rapidamente concentrações terapêuticas no líquido cefalorraquidiano (LCR), onde os valores correspondem a cerca de $60 \%$ dos níveis plasmáticos (faixa de 45 a 99\%) na presença ou ausência de meningite (FRIEDMAN et al., 1979), com efeito o fármaco pode acumular-se no tecido cerebral (KRAMER et al., 1969). No plasma, 30 $50 \%$ do cloranfenicol encontra-se ligado a proteínas. Sofre biotransformação hepática, onde é conjugado com o ácido glicurônico, sendo em seguida excretado na forma inativa, pelos rins.

Tem como indicações clínicas primárias, as infecções causadas por salmonelas, como a febre tifóide (ACKERS et al., 2000), infecções graves como meningite, epiglote ou pneumonia causada por H.influenzae (ALMEIDA-GONZÁLEZ et al., 2004), infecções meningocócicas ou pneumocócicas do sistema nervoso central (HERNANDEZ et al., 2003), infecções por riquétsias (CARRADA, 1986) e na brucelose (HIRINCHSEN et al., 2002).

O cloranfenicol é classificado na categoria C do FDA e seu uso durante a gestação ainda é muito controverso, pois apesar de atravessar a placenta com grande facilidade (PACIFICI \& NOTTOLI, 1995), atingindo altos níveis no feto, não há relatos na literatura sobre seu potencial teratogênico. Alguns autores relatam que em virtude de seu mecanismo de ação interferir com a síntese protéica, ele poderia alterar a síntese protéica fetal levando à malformações (ONUR et al., 1993). Entretanto, o único estudo retrospectivo sobre teratogenicidade humana com o uso do cloranfenicol relata, "dessa forma o uso do cloranfenicol durante os estágios iniciais da gestação não demonstrou qualquer padrão de teratogenicidade" (CZEIZEL et al., 2000).

Outros efeitos colaterais importantes que decorrem do uso do cloranfenicol são as alterações hematológicas que ele promove. O efeito hematológico mais importante é observado na medula óssea. O cloranfenicol afeta o sistema hematopoiético de duas maneiras: através de um efeito tóxico relacionado com a dose, que se manifesta em forma de anemia, leucopenia ou trombocitopenia, e através de uma resposta idiossincrática manifestada por anemia aplásica, que, em muitos casos, leva a pancitopenia fatal. Esta última resposta não está relacionada com a dose (SHU, 1987). Esses efeitos não foram encontrados em bebês nascidos de mães que utilizaram o fármaco durante a gestação (FEDER et al., 1981). Embora a literatura não tenha encontrado qualquer alteração no desenvolvimento e na viabilidade fetal, é no recém-nascido que reside o maior problema deste fármaco. Apesar da potencialidade hematotóxica do cloranfenicol ser conhecida, não são descritos danos hematológicos em fetos nascidos de mães que utilizaram o fármaco, exceto pela ocorrência de anemia em conceptos de cães e camundongos fêmeas que receberam altas doses e por tempo prolongado durante a gravidez (TAVARES, 2001).

Efeitos teratogênicos não foram observados nos conceptos de ratos (PROCHAZKA, 1964), coelhos (BROWN et al., 1968) e macacos (COURTNEY \& VALERIO, 1968) após tratamento com cloranfenicol na dose de 2 a 4 vezes a dose usual em humanos. Contudo, várias anomalias congênitas foram induzidas em ratos pelo tratamento materno com cloranfenicol na dose de 10 a 40 vezes a dose terapêutica em humanos (TAKAYA, 1965; DYBAN \& CHEBOTAR, 1971), mas não em camundongos e coelhos (FRITZ \& HESS, 1971).

Sua metabolização é essencialmente hepática e grandemente dependente de conjugação com o ácido glicurônico, sistema que ainda não está completamente desenvolvido no recém-nascido, principalmente nos prematuros (HOLT et al., 1995). A dificuldade de conjugar este fármaco e posterior excreção causa seu acúmulo nestes pacientes, levando ao aparecimento da chamada "síndrome cinzenta".

A síndrome geralmente começa 2-9 dias (em média 4 dias) após o início do tratamento. As manifestações nas primeiras 24 horas consistem em vômitos, recusa à sucção, respiração irregular e rápida, distensão abdominal, períodos de cianose e evacuação de fezes moles de coloração esverdeada. Todas as crianças mostram-se gravemente doentes no final do primeiro dia e, nas 24 horas seguintes, tornam-se flácidas, adquirem uma coloração acinzentada e apresentam hipotermia (ARMENTROUT \& WEISBERGER, 1967). Foi também relatada uma condição semelhante à síndrome cinzenta em adultos que receberam acidentalmente quantidades excessivas do fármaco e ou que tenham o seu funcionamento hepático alterado. Ocorre morte em cerca de $40 \%$ 
dos pacientes dentro de 2 dias após o aparecimento dos sintomas. Em geral, os pacientes que se recuperam não apresentam seqüelas (GOODMAN, 2003).

Dois mecanismos são aparentemente responsáveis pela toxicidade do cloranfenicol em recém-nascidos: 1) impossibilidade de conjugação do fármaco com o ácido glicurônico, devido à atividade inadequada da glicoruniltransferase no fígado, que é característica das primeiras 3-4 semanas de vida; e 2) excreção renal inadequada do fármaco não-conjugado no recém-nascido. Por ocasião do aparecimento da síndrome clínica, as concentrações plasmáticas de cloranfenicol geralmente ultrapassam $100 \mu \mathrm{g} / \mathrm{ml}$, embora possam ser tão baixas quanto $75 \mu \mathrm{g} / \mathrm{ml}$. A faixa terapêutica de concentração varia de 10 a $25 \mu \mathrm{g} / \mathrm{ml}$. Não se observaram efeitos tóxicos no recém-nascido quando foram administradas doses de $1 \mathrm{~g}$ do antibiótico a cada 2 horas a mulheres em trabalho de parto (CRAFT et al., 1974).

O processo metabólico no recém-nascido, responsável pela biotransformação do cloranfenicol ativo, tem sido descrito significativamente diminuído e altamente variável. Foi observada uma redução da atividade enzimática (glicuroniltransferase) em recém-nascido por não se encontrar desenvolvida, devido à imaturidade hepática, resultando em aumento de tempo para alcançar concentrações máximas de cloranfenicol ativo (até 4 horas) (HOLT et al., 1995).

\section{CONCLUSÕES}

A variabilidade no metabolismo e nos parâmetros farmacocinéticos do cloranfenicol em recém-nascidos, lactentes e crianças exige uma monitoração das concentrações plasmáticas do fármaco, sobretudo quando se administra concomitantemente um agente que potencialize o seu metabolismo, por exemplo, fenobarbital, fenitoína ou rifampicina. Em virtude do risco, embora pequeno de síndrome cinzenta no neonato e dos danos hematológicos causados pelo fármaco, recomenda-se que seu uso seja restrito a infecções em que não haja qualquer outra alternativa terapêutica eficaz. Deve apenas ser usado em casos em que o beneficio de seu uso seja maior que o seu risco.

\section{REFERÊNCIAS BIBLIOGRÁFICAS}

ACKERS, M.L.; et al. Laboratory-based surveillance of Salmonella serotype typhi infections in the United States: antimicrobial resistance on the rise. Journal of the American Medical Association, v. 283, p. 2668-2673, 2000.

ADDIS, A; SHARABI, S; BONATI, M. Risk classification systems for drug use during pregnancy: are they a reliable source of information? Drug Saf. v. 23, n.3, p. 245-253, sep 2000.

ALMEIDA-GONZÁLEZ, L.; et al. Enfermedad por meningococo, Neisseria meningitidis: epidemiological, clinical, and preventive perspectivas. Salud Pública de México. v.6, n.5, out. 2004.

ARMENTROUT, S. A.; WEISBERGER, A. S. Inibition of directed protein synthesis by chloramphenicol: effect of magnesium concentrion. Biochem biophys Res Commun. v. 27, p. 712, 1967.

BEELEY L. Adverse effects of drugs in later pregnancy. Clin Obstet Gynaecol. v. 13, p. 197-214, 1986.

BERNE, R. M.; LEVY, M. N. Fisiologia. 4ª ed. Rio de Janeiro: Guanabara Koogan, 2000. p. 947.

BHUTA, P.; et al. Analogues of chloramphenicol: circular dichroism spectra, inhibition of ribosomal peptidyltransferase, and possible mechanism of action. J Med Chem. v. 23, n. 12, p. 1299-1305, dec. 1980 .

BROWN, D. M.; et al. Effect of antibiotics uppon the rabbit. Toxicol Appl Pharmacol. v. 12, p. 295, 1968.

CARRADA, B. T. Fiebre maculosa americana em niños: avances y perspectivas. Ver. Mex. Pediatr., v.53, n.4, p. 133, 134, 137, 141-144, ago. 1986.

CHRISTENSEN, B. Which antibiotics are appropriate for treating bacteriuria in pregnancy? $\mathrm{J}$ Antimicrob Chemother. v. 1, p.29-34, 2000.

COURTNEY, K. D.; VALERIO, D. A. Teratology in the Macaca mulatta. Teratology, v. 1, p. 163-172, 1968.

CRAFT, A. W.; et al. The grey toddler: chloramphenicol toxicity. Arch. Dis. Child. v. 49, p. 235-237, 1974.

CZEIZEL, A. E.; et al. A population-based case-control teratologic study of oral chloramphenicol treatment during pregnancy. European Journal of Epidemiology, v. 16, p. 323-327, mar. 2000.

DASHE, J. S.; GILSTRAP, L. C. Antibiotic use in pregnancy. Obstet Gynecol Clin North Am. v. 24, n. 3, p. 617-629, 1997. 
DYBAN, A. P.; CHEBOTAR, N. A. Can cleft palate be induced by chloramphenicol? Arch. Anat., v. 60, p. 25-29, 1971.

FEDER H. M. J.; OSIER, C.; MADERAZO, E. G. Chloramphenicol: a review of its use in clinical practice. Rev Infect Dis. v. 3, n. 3, p. 479-491, may.-jun. 1981.

FRIEDMAN, C. A.; LOVEJOY, F. C.; SMITH, A. L. Chloramphenicol disposition in infants and children. J. Pediatr., v. 95, p. 1071-1077, 1979.

FRITZ, H.; HESS, R. The effect of chloramphenicol on the prenatal development of rats, mice, and rabbits. Toxical Appl Pharmacol, v. 19, p. 667-674, 1971.

GOMES, K. R.; et al. Prevalence of use of medicines during pregnancy and its relationship to maternal factors. Rev Saude Publica. v. 33, n. 3, p. 246-254, 1999.

GOODMAN, G. A. As bases farmacológicas da terapêutica. 10a ed. Rio de Janeiro: Mac Graw Hill, 2003. p. 934937.

GREENWOOD, D. Inhibitors of bacterial protein synthesis. In: Greenwood D (ed) Antimicrobial chemotherapy, $3^{\mathrm{a}}$ ed., Oxford University Press, 1997. p. 32-48.

HERNANDEZ, M.; et al. Evidencia in vitro de la utilidad de cloranfenicol y rifampicina para el tratamiento de infecciones sistémicas y meningitis causadas por Streptococcus pneumoniae aislados de niños menores de 5 años en Colombia. Biomédica (Bogotá), v. 23, n. 4, p. 456-461, 2003.

HIRINCHSEN, S. L.; et al. Brucelose: relato de caso. An. Fac. Méd. Univ. Fed. Pernambuco, v. 47, n.2, p. 148-152, 2002.

HOLT, D. E.; HURLEY, R.; HARVEY, D. Metabolism of chloramphenicol by glutathione S-transferase in human fetal and neonatal liver. Biol Neonate. v. 67, n. 4, p. 230-239, 1995.

KRAMER, P. W.; GRIFFITH, R. S.; CAMPBELL, R. L. Antibiotic penetration of the brain: a comparative study. J Neurosurg, v. 31, p. $295-302,1969$.

MENGUE, S. S.; et al. Drug use by pregnant women in six Brazilian cities. Rev Saude Publica. v. 35, n. 5, p. 415420, 2001.

MENGUE, S. S.; et al. Fatores associados ao uso de medicamentos durante a gestação em seis cidades brasileiras. Cad. de Saúde Pública, Rio de Janeiro, v. 20, n. 6, 2004.

MYLLYNEN, P.; PASANEN, M.; PELKONEN, O. Human placenta: a human organ for developmental toxicology research and biomonitoring. Placenta. v. 26, n. 5, p. 361-371, may. 2005.

MOORE, K. L. The developing human; clinically oriented embryology. $3^{\mathrm{a}}$ ed. Philadelphia: Saunders, 1982, p.14166.

NIEBYL, JR. Therapeutic drugs in pregnancy: caution is the watchword. Postgrad Med. v. 75, n. 8, p. 165-166, 169-172, 1984.

ONUR, M. A.; et al. Decrease in the placental transfer of chloramphenicol when administered in albumin microspheres into rats. J Microencapsul. v. 10, n. 3, p. 367-374, jul.-sep. 1993.

PACIFICI, G. M.; NOTTOLI, R. Placental transfer of drugs administered to the mother. Clinical Pharmacokinetic Concepts, Pisa - Itália, v. 28, n. 3, p. 235- 269, 1995.

PETERS, W. Risk assesment of drug use in pregnancy: prevention of birth defects. Ann Ist Super Sanitá, v. 26, p. 131-137, 1993.

PHILIPSON, A.; STIERNSTEDT, G.; EHRNEBO, M. Comparison of the pharmacokinetics of cephradine and cefazolin in pregnant and non-pregnant women. Clin Pharmacokinet. v.12, n. 2, p.136-144, 1987.

PRESTON, S. L. The importance of appropriate antimicrobial dosing: pharmacokinetic and pharmacodynamic considerations. Ann Pharmacother. v.38, n. 9, p.14-18, 2004.

PROCHAZKA, J.; SIMKOVA, V.; HAVELKA, J. Concerning the penetration of the placenta by chloramphenicol. Pediatria, v. 19, p. 311-314, 1964.

RAO, J. M.; ARULAPPU, R. Drug use in pregnancy: how to avoid problems. Drugs. v. 22, n. 5, p.409-414, nov. 1981.

REYES, B.; et al. El cloranfenicol: 40 años después. Infectologia, v. 7, n. 4, p. 151-162, abr. 1987.

RUIZ, N. M.; RAMIREZ-RONDA, C. H. Tetracyclines, macrolides, lincosamides \& chloramphenicol. Bol Asoc Med P R. v. 82, n. 1, p. 8-17, jan. 1990. 
SÁ DEL FIOL, F.; ROCHA, M. F. T.; GROPPO, F. C. Evaluation in an animal model and in vitro of the combination clavulanic acid and cephalosporins against beta-lactamase producing and nonproducing Staphylococcus aureus strains. Braz J Infect Dis. v. 4, n. 1, p. 36-42, 2000.

SHU, X. O. Chloramphenicol use and childhood leukemia in Shanghai. Lancet, v. 2, p. 934-937, 1987.

TAKAYA, M. Teratogenic effects of antibiotics. J. Osaka City Med. Cent., v. 14, p. 107-115, 1965.

TAVARES, W. Manual de antibióticos e quimioterápicos antiinfecciosos. $3^{\mathrm{a}}$ ed. São Paulo: Atheneu, 2001. p. 292.

WHIPKEY, R. R.; PARIS, P. M.; STEWART, R. D. Drug use in pregnancy. Ann Emerg Med. v. 13, p. 346-354, 1984. 